\title{
Modelling the cyclic influence of climate change on the world economic system
}

\author{
Andrey Zaytsev ${ }^{1 *}$, Evgeniy Konnikov ${ }^{1}$, Yuliya Asaturova ${ }^{1}$ and Svetlana Didenko ${ }^{1}$ \\ ${ }^{1}$ Peter the Great St. Petersburg Polytechnic University, Saint Petersburg, Russia
}

\begin{abstract}
Global climate change has become one of the central problems of the world economy over last decades. Its impact on the economy forces it to adapt to the new conditions. Increasing carbon dioxide $\left(\mathrm{CO}_{2}\right)$ emissions, resulting in the greenhouse effect, depletion of natural resources, pollutions and health problems directly caused by achievements of the industrial revolution have been catastrophic for the environment. The object of the research in this work is the world economic system. The aim of the research is to analyze the factors affecting climate change and to produce recommendations for preventing the negative impact of human economic activity on the world economic system. As a result of the research, four basic econometric models have been built: 1) dependence of temperature change on $\mathrm{CO}_{2}$ emissions; 2) dependence of the number of disasters on temperature change; 3 ) dependence of the world GDP on the number of disasters; 4) dependence of $\mathrm{CO}_{2}$ emissions on GDP. According to the results of econometric research, this study obtained working conceptual model, which describes cyclic influence of the four interrelated factors, forming a closed system. Thus, the work proves that there is a cyclic relationship between climate change and the state of the world economy.
\end{abstract}

\section{Introduction}

Global climate change has become the most acute problem for the world economy and policy over the last two decades. Having an impact on the global economy independently on the wishes of specific countries, it is now perceived as an essential element of the new reality to which all the countries and all humankind have to adapt their economic activities [1]

One of the key factors affecting climate change is human impact, in particular, carbon dioxide emissions in the atmosphere. Increasing emissions of carbon dioxide and its growing concentration in the air are changing the carbon cycle mechanism established many hundred years ago. Together with other gases, it affects the greenhouse effect on the planet, which has a general tendency towards growing and causes climate change [2].

Apart from temperature rise, one of the signs of climate change is that natural disasters occur more frequently. They negatively affect all levels of human life. Earthquakes, hurricanes, landslides take thousands of human lives and inflict huge economic losses on countries, companies, and people. Moreover, their effects are especially noticeable in

* Corresponding author: zajtsev.aa@ spbstu.ru 
countries with a low socioeconomic development level, where the recovery process can take dozens of years [3].

This work lays out the details of the cyclic influence of four factors, which reveal each other's impact in the most precise way. $\mathrm{CO} 2$ emission produced in the course of the world economic activities is taken as the human impact on climate since carbon dioxide production accompanies virtually all types of human activities [4]. Manufacturing and transporting goods, generating electricity are not possible without $\mathrm{CO} 2$ emissions.

The average change in air temperature and the number of cataclysms in the world play a role in climate change. These very two indicators started to grow after the industrial revolution, when there was a mass transfer from manual to machine labor, from craft production to a factory. The depletion of natural resources, carbon emissions, pollutions, and health problems caused directly by the Industrial Revolution's achievements have been disastrous for the global environment [5].

More frequent natural disasters and change in natural climate are noticeable in every country. The effects of floods, hurricanes and extreme temperatures stop the production activities of the regions where these disasters occur. It cannot but affect the gross domestic product of the country and its position on the global stage. Thanks to this, the value of GDP at current prices was chosen to evaluate the state of the world economy [6].

This study see that the climate change taking place in recent decades has a negative impact on the world economy. Therefore, modeling the impact of climate change on the global economic system is especially important. Literary sources usually track the influence of individual factors on climate change. Therefore, special emphasis in this work will be given to a comprehensive cyclical assessment of the impact of climate change factors on the economy.

More frequent natural disasters and changes in natural climate are noticeable in every country. The effects of floods, hurricanes, and extreme temperatures stop the regions' production activities where these disasters occur. It cannot but affect the country's gross domestic product and its position on the global stage. Thanks to this, the value of GDP at current prices was chosen to evaluate the state of the world economy [6].

This study shows that the climate change taking place in recent decades negatively impacts the world economy. Therefore, modeling the impact of climate change on the global economic system is especially important. Literary sources usually track the influence of individual factors on climate change. Therefore, special emphasis in this work will be given to a comprehensive cyclical assessment of climate change factors' impact on the economy.

This research aims to analyze the factors that influence climate change and develop a conceptual model to assess the cyclic influence of climate change factors on the world economic system.

To reach this goal, the following objectives have to be fulfilled:

1. The theoretical basis of the research has to be analyzed.

2. The research methodology has to be substantiated.

3. It is necessary to develop the main econometric models measuring the impact of various factors on global climate change and the world economy.

4. It is necessary to build a conceptual model that reflects the four interrelated factor's influence on the world economic system.

5. Recommendations have to be produced on how to prevent the negative human impact on climate.

The research object is the world economic system, while the research subject is the climate change caused by the influence of anthropogenic factors on the world economy.

This work will be of interest for wide audience, specialists in the economic sphere helping them to prevent possible crises caused by environmental disasters, and ecologists for 
understanding a number of factors that influence climate. Moreover, it can be useful for everyone's information.

\subsection{Literature review}

Further, this study looks at more specific research studies used by the authors to build econometric models. So far, scientists have not adopted a single position towards global warming. Some researchers believe that global warming is caused by increasing solar activity, and human actions cannot have such a large-scale effect. Others think that climate is changing because the environment is affected by humankind's economic activities and offers persuasive evidence supported by empirical research [36].

One of the major causes of carbon dioxide production is international trade. An impressive example is a growing impact of polluted air on human health in China caused by the export production of goods for developed countries. Transporting and relocating production between countries contradict the national policy of mitigating climate change and can wipe away the obvious achievements in lessening the effects of economic growth [37].

The study by [38] creates a model of climate change and its consequences for humankind. According to this study, it can be concluded that the annual temperature rise will cause more cataclysms. A forecast is made, and it says that the temperature change rate is bound to grow and, therefore, the number of disasters will increase too. The authors of the paper suggest considering the change in climate conditions when organizing infrastructure and adapting the existing structures with due regard of possible changes.

One more work is dedicated to possible adaptations to climate change, considered in the context of Russia. The author says that climate insurance development is becoming an important factor on the way to adaptation. This type of insurance can reduce the strain on the state budget in case the frequency of extreme weather conditions rises. In the author's opinion, one of the main problems for Russia is afforestation and reforestation. "These measures do not require considerable investment, but the expected results are really impressive in terms of environment and economy: reduced risk of floods, improved quality of the air environment, increased recreational attractiveness of forested areas, etc.» [39].

All scientists unanimously agree that the impact of climate change on the economic system is obvious. In his work [40] discusses the major problems arising in the analysis of global climate change. The author makes an accent on analyzing the main negative effects of climate change on the world economic system:

- climate change has an impact on agricultural production. It is shown that even $1{ }^{\circ} \mathrm{C}$ temperature increase can reduce the yield of three major crops - wheat, rice and corn - by $10 \%$.

- gradual melting of the ice caps of the Earth, a growing number of hurricanes and floods can make the sea level rise, and will eventually affect the well-being of coastal areas.

- climate change leads to more frequent hydro-meteorological natural disasters: floods, droughts, storms, hurricanes, heatwaves and cold waves.

- climate change also makes an impact on the health of the world population because the human body needs to get adapted to new climate conditions; global warming may lead to expanding the niduses of dangerous tropical diseases to the north;

- climate change can aggravate the deficit of fresh water caused by demographic and economic growth.

- climate change can have a negative effect on the operation of many eco-systems [41].

It is obvious that climate change will also affect the global economic situation. The research study "Dependence of the economic consequences of climate change on human- 
induced paths" discusses the creation of various models of the climatic effect on countries' economic activities. According to the study, in the worst-case scenario, if no action is taken to lessen the consequences, it will have resulted in the net economic effect equivalent to $6.6 \%$ (3.9-8.6\%) of the gross world product by the end of this century. In case rigid measures are taken, the effect can be limited down to $1 \%$ or even less.

The states most vulnerable to natural disasters are developing countries. A. Sabunchi [42] note that among the most destructive natural disasters are tsunami, floods, tropical storms and typhoons: «They account for about $2 / 3$ of the total number of natural cataclysms. The remaining third includes earthquakes and drought. Most of these disasters occur in Asia while developing countries account for over $95 \%$ of human life loss due to natural disasters. The losses of these countries (as GDP percentage) can exceed the losses of industrially developed countries by 20 times»».

It should be noted that climate change will primarily affect crop production [43]. Abnormal temperatures, droughts, and floods dramatically reduce yield, in particular, the yield of cereals. Understanding the key processes leading to yield losses helps to substantiate the priorities of actions aimed at reducing the risk of disasters and take adaptation measures to protect most vulnerable agricultural systems and populations depending on them.

In his article Stephane Hallegatte described one of the solutions to the effect of climate change for the activities of transnational companies [44]. In order to increase their sustainability on the world stage in case of natural disasters, companies should increase their stocks and/or increase the number of potential suppliers. These measures will help companies to secure themselves against any unforeseen situations.

The banking system will be in a vulnerable position too. The results of one research study show that climate change will increase the frequency of bank crises (26-28\%), and saving insolvent banks will cause an additional strain in the amount of about 5-15\% of GDP per year and double the GDP to national debt ratio. At the same time financial regulation may play a role in mitigating the effects of climate change [45, 46].

Thus, the analysis of literary sources has shown a large number of works raising the problem of the influence of various factors on climate change and, as a consequence, on the world economic system. However, not enough attention is paid to a comprehensive cyclical assessment of the impact of factors on climate change. In the proposed work, for a detailed analysis, this study selected four interrelated factors: $\mathrm{CO} 2$ emissions, temperature change, the number of disasters and GDP level, so it is in these factors that cyclical interaction with each other is most manifested. 


\section{Method}

In this work, a pair regression is applied for econometric modeling. The four variables considered are taken for the period of 1980-2017. Table 1 contains the symbols of the variables and their sources.

Table 1. Variables for econometric modelling.

\begin{tabular}{|c|c|c|c|}
\hline $\begin{array}{c}\mathrm{CO}_{2} \\
\text { emissions }\end{array}$ & $\mathrm{W}$ & bil. tons & https://www.icos-cp.eu/GCP/2018 \\
\hline $\begin{array}{c}\text { Temperature } \\
\text { change }\end{array}$ & $\mathrm{X}$ & $0.01 \mathrm{C}^{\circ}$ & $\begin{array}{c}\text { https://data.giss.nasa.gov/gistemp/ } \\
\text { tabledata_v3/GLB.Ts+dSST.txt }\end{array}$ \\
\hline Disasters & $\mathrm{Y}$ & units & $\begin{array}{c}\text { https://ourworldindata.org/grapher/ } \\
\text { number-of-natural-disaster-events }\end{array}$ \\
\hline $\mathrm{GDP}$ & $\mathrm{Z}$ & bil. USD & $\begin{array}{c}\text { https://businessforecast.by/partners/ } \\
\text { ratings/rejting-stran-mira-po-urovnju-vvp-v-1980- } \\
\text { 2018-gg/ }\end{array}$ \\
\hline
\end{tabular}

They have an impact on each other in a certain sequence. It should be noted that the influence of temperature on the number of cataclysms in calculations is considered with one year interval. It is because the consequences of some processes do not have simultaneous reflection. Some, for instance, temperature change need time to produce an effect. Table 2 contains the values of variables.

Table 2. Source data for econometric modelling

\begin{tabular}{|c|c|c|c|c|c|c|c|c|c|}
\hline Year & $\mathrm{W}$ & $\mathrm{X}$ & $\mathrm{Y}$ & $\mathrm{Z}$ & Year & $\mathrm{W}$ & $\mathrm{X}$ & $\mathrm{Y}$ & $\mathrm{Z}$ \\
\hline 1980 & 5292 & 27 & 133 & 10711 & 1999 & 6531 & 40 & 337 & 31377 \\
\hline 1981 & 5127 & 33 & 138 & 10940 & 2000 & 6703 & 40 & 411 & 32331 \\
\hline 1982 & 5083 & 13 & 153 & 10840 & 2001 & 6861 & 53 & 376 & 32130 \\
\hline 1983 & 5063 & 32 & 205 & 11110 & 2002 & 6958 & 62 & 421 & 33403 \\
\hline 1984 & 5245 & 16 & 146 & 11545 & 2003 & 7333 & 60 & 360 & 37528 \\
\hline 1985 & 5402 & 12 & 165 & 11956 & 2004 & 7693 & 53 & 350 & 42229 \\
\hline 1986 & 5567 & 18 & 150 & 14089 & 2005 & 7984 & 67 & 432 & 45679 \\
\hline 1987 & 5708 & 33 & 191 & 16176 & 2006 & 8266 & 62 & 401 & 49452 \\
\hline 1988 & 5917 & 41 & 200 & 18159 & 2007 & 8428 & 64 & 414 & 55827 \\
\hline 1989 & 6046 & 29 & 172 & 19062 & 2008 & 8700 & 51 & 352 & 61364 \\
\hline 1990 & 6054 & 44 & 278 & 22196 & 2009 & 8603 & 63 & 344 & 57983 \\
\hline 1991 & 6122 & 41 & 228 & 23274 & 2010 & 9025 & 70 & 393 & 63468 \\
\hline 1992 & 6058 & 22 & 204 & 24356 & 2011 & 9377 & 58 & 334 & 70221 \\
\hline 1993 & 6046 & 24 & 260 & 24999 & 2012 & 9530 & 62 & 346 & 71707 \\
\hline 1994 & 6150 & 31 & 246 & 26825 & 2013 & 9609 & 65 & 332 & 74172 \\
\hline 1995 & 6279 & 45 & 248 & 29825 & 2014 & 9690 & 73 & 320 & 77805 \\
\hline 1996 & 6420 & 34 & 227 & 30547 & 2015 & 9679 & 87 & 380 & 82147 \\
\hline 1997 & 6527 & 47 & 261 & 30417 & 2016 & 9737 & 99 & 325 & 86906 \\
\hline 1998 & 6546 & 62 & 288 & 30202 & 2017 & 9867 & 90 & 276 & 92094 \\
\hline
\end{tabular}

In pair regression analysis, one should be guided by the indicators showing how reliable and significant is the model obtained as a result of the analysis. The following algorithm can be used to conduct this research:

1. Checking the multicollinearity of the studied factors for each model. 
2. Excluding multicollinear factors.

3. Evaluating the parameters of each model.

4. Projecting regressor values for the period of test sample.

5. Estimating the values of endogenic variables for the period of test sample.

6. Evaluating the quality of the forecast.

7. Producing recommendations to prevent the negative impact of human economic activities.

\section{Results and discussion}

\subsection{Results}

The research results can be systematized by four major econometric models:

1. Dependence of temperature change on $\mathrm{CO}_{2}$ emissions;

2. Dependence of the number of disasters on temperature change;

3. Dependence of world GDP on the number of disasters;

4. Dependence of $\mathrm{CO}_{2}$ emissions on GDP.

Let us first look at the pair regression of each model.

\subsubsection{Model 1: Dependence of temperature change on $\mathrm{CO}_{2}$ emissions}

This model considers the impact of $\mathrm{CO}_{2}$ emissions on temperature change. Figure 1 illustrates a logarithmic dependence of indicators. The coefficient of determination of Model 1 is equal to 0.785 , so it can be concluded that the model is quite effective.

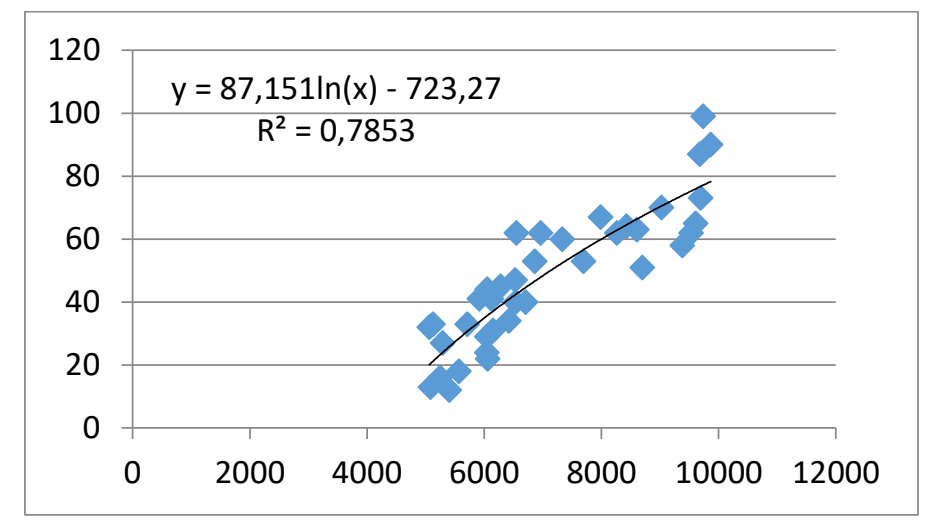

Fig. 1. Trend line graph of Model 1.

It should be considered that the true causes of temperature change still cause controversy among scientists. Despite this fact, based on the research, it can be concluded that carbon dioxide emissions are very likely to impact temperature change $(p$-level $=0.00002986)$. Moreover, this study can assume that Model 1 is at an adequate quality level, since the Fcriterion's significance is small (2.58E-13). The final criterion, approximation error is $0.21 \%$. Correspondingly, the model obtained is quite reliable.

Based on these criteria, this study can conclude that carbon dioxide emissions are directly proportional to temperature change, which does not contradict logic. The predicted value exactly repeats the actual value. There are no emissions that exceed confidence limits. However, there is a structural break in the last period, which means that the details of the 
interaction of the independent variable with the external environment can change. So, it is possible to say that carbon dioxide emissions increase the average annual temperature.

\subsubsection{Model 2: Dependence of the number of disasters on temperature change}

This model considers the impact of temperature on the number of disasters. Figure 2 represents a polynomial dependence of indicators. The coefficient of determination of Model 1 is equal to 0.532 , so the model has the right to exist.

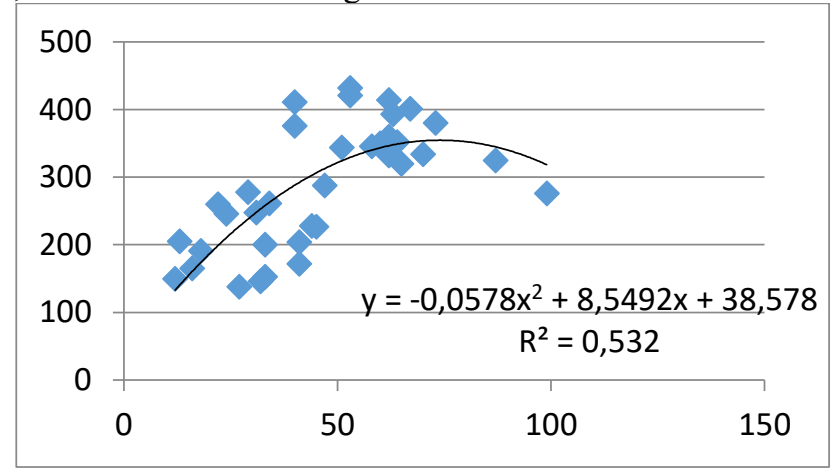

Fig. 2. Trend line graph of Model 2.

It should also be taken into account that the main causes of cataclysms have not been explained by scientists yet. Despite this fact, according to the research it can be concluded that temperature change is very likely to affect the number of disasters ( $\mathrm{p}$-level=3.86E-06). Moreover, this study can conclude that Model 2 is high quality as the F-criterion's significance is quite small (1.7E-07). The final criterion, approximation error amounts to $0.24 \%$, so the model obtained is quite reliable.

Based on these criteria this study can claim that the average annual temperature change has an impact on the number of cataclysms. It should be highlighted that the trend line is a polynomial of the second power, which means that when exceeding a certain limit, temperature rise stops increasing the number of disasters. It can be explained by the fact that some other factors, apart from temperature rise, which has not been defined by scientists yet, can change the nature of the impact of both air and water temperature on the quantity and scale of disasters. The projected model contains several structural breaks and emissions that exceed confidence limits. It means that in certain cases the negative impact of such factors as human activities is possible. So it can be concluded that temperature change affects the number of disasters under conditions of our model.

\subsubsection{Model 3: Dependence of GDP level on the number of disasters}

This model considers the impact of the number of disasters on the level of world GDP. Figure 3 illustrated the power dependence of indicators. The coefficient of determination of Model 1 is equal to 0.68 . Hence, the model is significant. 


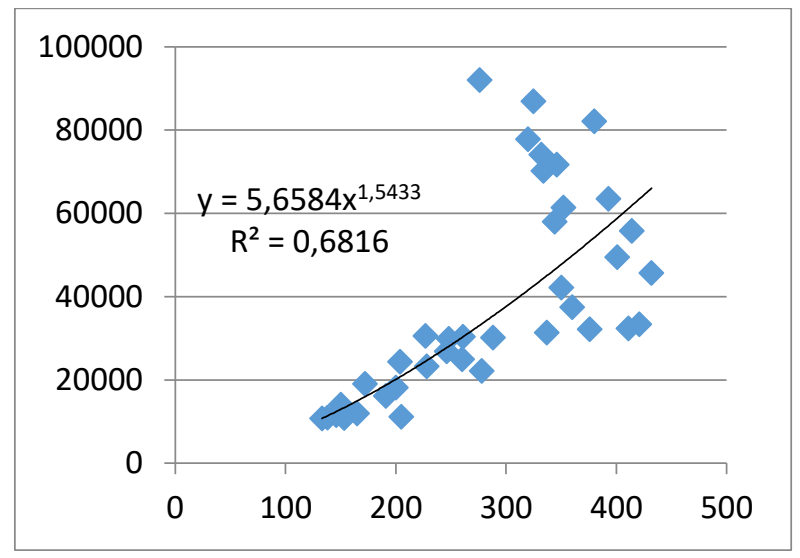

Fig. 3. Trend line graph of Model 3.

It should be considered that the value of the gross world product is affected by a number of factors that cannot be assessed, for example an economic situation or external national policy. Due to such factors, the P-level indicator's value is 0.307 , so this study cannot conclude that it is quite probable that cataclysms influence the value of GDP ( $p$-level=0.307). But this study can deduce that Model 3 is high quality since the significance of the F-criterion is quite small (8.33E-06). The final criterion, approximation error is $0.48 \%$, so our model is reliable.

Based on these criteria this study can claim that the number of natural disasters affect the world GDP indicator, which does not contradict logic. The projected model has several structural breaks and emissions that exceed confidence intervals. It means that the size of the gross world product is affected by other factors. Thus, it can be concluded that the number of disasters influences the world GDP under conditions of our model.

\subsubsection{Model 4: Dependence of $\mathrm{CO}_{2}$ emissions on GDP}

This model considers the impact of the gross world product on the amounts of $\mathrm{CO}_{2}$ emissions. Figure 4 presents a polynomial dependence of indicators. The coefficient of determination of Model 4 is 0.99 , which allows us to conclude that the model is quite effective.

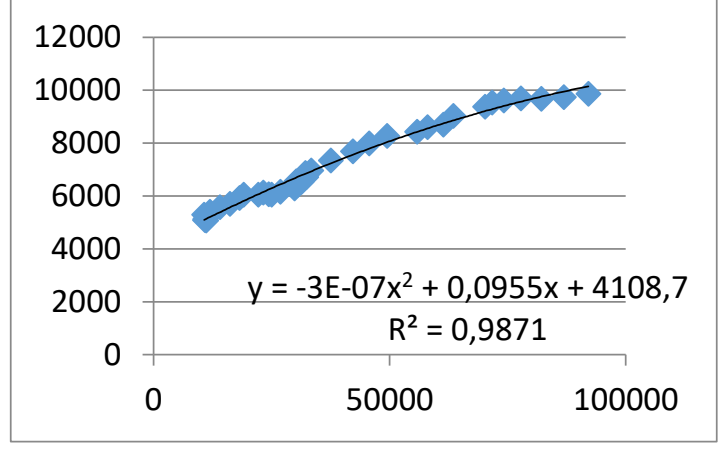

Fig. 4. Trend line graph of Model 4.

It is important to highlight that the amounts of $\mathrm{CO} 2$ emissions are mostly affected by the state policy in the production sector. According to the research it can be concluded that GDP is very likely to have an impact on CO2 emissions ( $\mathrm{p}$-level=1.29E-37). Moreover, this study can deduce that Model 4 is at an adequate quality level, since the F-criterion's significance is 
very small (9.56E-31). The last criterion, approximation error is $0.035 \%$, so the model obtained is quite reliable.

Based on these criteria this study can claim that GDP strongly affects $\mathrm{CO} 2$ emissions, which does not contradict logic. The predicted value exactly repeats the actual value. There are no emissions that exceed confidence intervals. So it can be concluded that GDP increases carbon dioxide emissions.

\section{Conclusion}

The work's main result is the developed conceptual model of the cyclic influence of factors on the world economic system (Figure 5). It describes the cyclic impact of four interrelated factors that form a closed system. Four econometric models, illustrating a pair regression of individual interrelated factors, were built in the context of the conceptual model. Thus, the relationship between climate change and the state of the world economy has been proven.

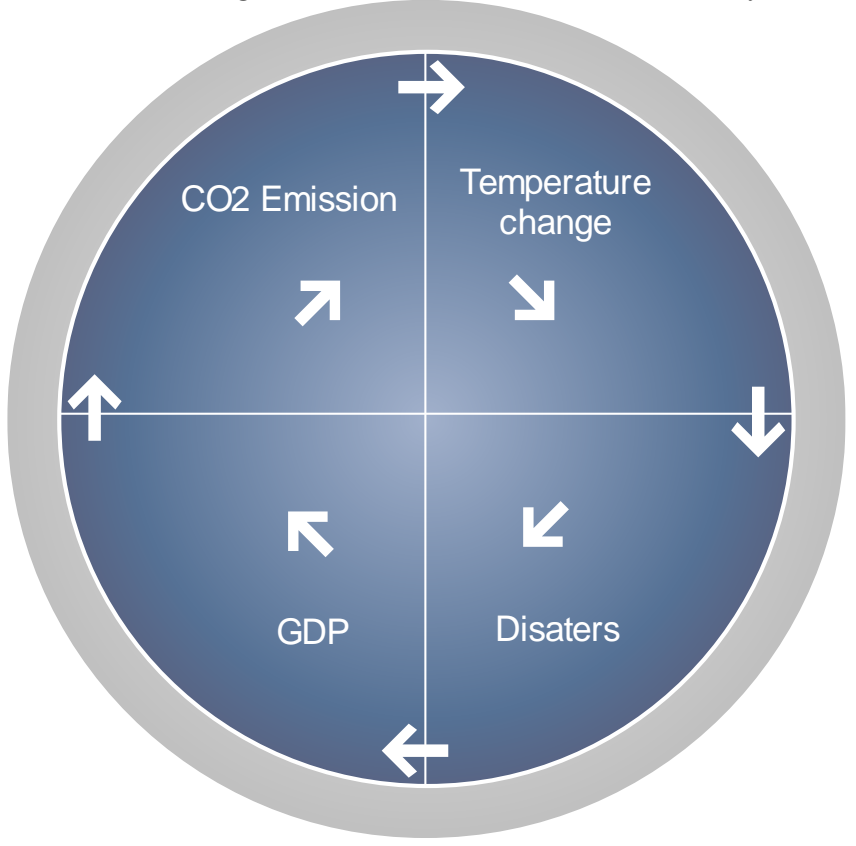

Fig. 5. Model of cyclic impact of factors on the world economic system.

It should be noted that the results of the analysis of the influence of various factors on climate change carried out in the work are in accordance with the data of modern empirical studies $[16,28,38,43,44]$ however, a comprehensive assessment of the cyclic interaction of factors was made for the first time and is the original result of the authors.

The final model has significance at all levels of human life and activities. It should also be noted that economic growth is accompanied with bigger and bigger emissions of carbon dioxide. Based on this research a conclusion can be drawn that further inaction to prevent air pollution will result in a collapse of the existing economic system.

This trend can be reversed if climate change is accepted as a factor of economic development. Supporting alternative, renewable sources of energy will help to reduce carbon dioxide emissions in the energy sector. Developing electric engines will diminish waste from production activities. Moreover, government support of local production will dramatically reduce waste caused by transportation of goods. 
Apart from decreasing emissions, it is worth reconsidering the existing economic system and adapting it to the possible natural disasters. Readiness to face cataclysms and/or to quickly compensate damage caused by natural disasters is a must in the most vulnerable regions.

\section{Acknowledgements}

This research work was supported by the Academic Excellence Project 5-100 proposed by Peter the Great St. Petersburg Polytechnic University.

\section{References}

1. G. R. Walther, E. Post, P. Convey, A. Menzel, C. Parmesan, T. J. C.Beebee, J. M. Fromentin, O. Hoegh-Guldber, F. Bairlein, Ecological responses to recent climate change, Nature, 416 (2002) https://doi.org/10.1038/416389a

2. M. Jarraud, A. Steiner, Managing the Risks of Extreme Events and Disasters to Advance Climate Change Adaptation, Special Report, 7 (2012) https://doi.org/10.1017/CBO9781139177245.00

3. D.G. Rodionov, I.A. Rudskaya, Regional innovatıve environment in natıonal economic development, Int. J. of Eco. and Dev. 32, 4 (2017)

4. E. Abushova, E. Burova, S. Suloeva, A. Shcheglova, Complex approach to selecting priority lines of business by an enterprise, in Proceedings of 6th International

Conference on Reliability, Infocom Technologies and Optimization: Trends and Future Directions, ICRITO, 22-22 September 2017, Noida, India (2018) https://doi.org/10.1109/ICRITO.2017.8342491

5. A.E.Skhvediani, T.Y. Kudryavtseva, The socioeconomic development of Russia: Some historical aspects. Eur. Res. St. J. 21, 4 (2018)

6. E.A. Gorbashko, S.A. Leonov, E.D. Malevskaia-Malevich, The current state and future trends of the textile branch of the light industry of Russia. Izvestiya Vysshikh Uchebnykh Zavedenii,. 1 (2019)

7. C.H. Richter, X. Jianchu, B.A. Wilcox, Opportunities and challenges of the ecosystem approach, Futures, 67 (2015) https://doi.org/10.1016/j.futures.2014.12.002

8. V. Roblek, M. Meško, A. Krapež, SAGE Open, 1 (2016) https://doi.org/10.1177/2158244016653987

9. E. Sisinni, A. Saifullah, S. Han, U. Jennehag, M. Gidlund, Industrial internet of things: Challenges, opportunities, and directions. IEEE, 14, 11 (2018) https://doi.org/10.1109/TII.2018.2852491

10. A. Zaytsev, D. Rodionov, N. Dmitriev, O. Kichigin, Comparative analysis of results on application of methods of intellectual capital valuation, in Proceedings of DTMIS 2019, Russia, St. Petersburg (2019)

11. J.C. Graff, J.A. Foran, The environment, in Health Care for People with Intellectual and Developmental Disabilities Across the Lifespa (2016) https://doi.org/10.1007/978-3-319-18096-0_30

12. J. Asaturova, Peculiarities of development of industry 4.0 concept in Russia, in IOP Conference Series: Materials Science and Engineering, 497,1 (2019) https://doi.org/10.1088/1757-899X/497/1/012039 
13. D.G. Rodionov, T.J. Kudryavtseva, A.E. Skhvediani, Human development and income inequality as factors of regional economic growth, Eur. Res. St. J, 21, 2 (2018)

14. A. Dai, Drought under global warming: A review, Climate Change, 5 (2011) https://doi.org/10.1002/wcc.81

15. Intergovernmental Panel on Climate Change. Climate Change 2014: Mitigation of Climate Change, IPCC $5^{\text {th }}$ Assessment Report (2014) https://doi.org/10.1017/cbo9781107415416

16. W. Lyles, M. Stevens, Climate change, The Routledge Handbook of International Planning Education (2019) https://doi.org/10.4324/9781315661063-25

17. I.M. Held, B.J. Soden, Robust responses of the hydrological cycle to global warming, J. Climate, 19, 21. (2006) https://doi.org/10.1175/JCLI3990.1

18. C.D. Thomas, A. Cameron, R.E. Green, M. Bakkenes, L.J. Beaumont, Y. C. Collingham, B.F.N. Erasmus, M. Siqueira, A. Grainger, L. Hannah, L. Hughes, B. Huntley, A.S. Jaarsveld, G.F. Midgley, L. Miles, M. A. Ortega-Huerta, A.T. Peterson, O. L. Phillips, S.E. Williams, Extinction risk from climate change. Nature, 427 (2004) https://doi.org/10.1038/nature0212 1

19. K.E. Trenberth, A. Dai, G. Schrier, P.D. Jones, J. Barichivich, K.R. Briffa, J. Sheffield, Global warming and changes in drought, Nature Climate Change, 4 (2014) https://doi.org/10.1038/nclimate2067

20. V.M. Abramov, I.V. Aleshin, V.G. Burlov, A.N. Chusov, E.P. Istomin, M.B. Shilin, A.G. Sokolov, Geo-information and geo-ecological support tools development for environmental economics, in Proceedings of the 33rd IBIMA Conference (2019)

21. C.S. Holling, Resilience and stability of ecological systems, in The Future of Nature: Documents of Global Change (2013) https://doi.org/10.1146/annurev.es.04.110173.000245

22. E.S. Balashova, E.A. Gromova, Lean production in the context of housing and civil engineering in arctic, Espacios, 38 (2017)

23. E.A. Konnikov, O.A. Konnikova, D.G. Rodionov, Impact of 3D-Printing Technologies on the Transformation of Industrial Production in the Arctic Zone, Resources, 8, 1 (2019) https://www.mdpi.com/2079-9276/8/1/20

24. I. Rudskaya, D. Rodionov, Econometric modeling as a tool for evaluating the performance of regional innovation systems, Academy of Strategic Management Journal, 16, 2 (2017)

25. E.S. Reed, The Ecological Approach to Visual Perception, Yale Un. Press, 1 (2018) https://doi.org/10.2307/j.ctt1xp3nmm.20

26. A.B. Bekbaev, K.B. Shakenov, V.V. Titkov, Analysis of the roof of an autonomous house for efficient use of wind energy, EAI Endorsed Transactions on Energy Web. 19, 21 (2019)

27. T.M. Bugaeva, O.V. Novikova, Modern methods of urban energy system planning. Energetika, in Proceedings of CIS Higher Education Institutions and Power Engineering, 62,4 (2019)

28. O.E. Kichigin, Fossil fuel production impact on regional eco-economic development. Int. J. of Ecological Economics and Statistics. 38, 4 (2017)

29. A. Jeliazkov, D. Mijatovic, S. Chantepie, A global database for metacommunity ecology, integrating species, traits, environment and space, Scientific Data, 7,1 (2020) https://doi.org/10.1038/s41597-019-0344-7 
30. E. Ostrom, A general framework for analyzing sustainability of social-ecological systems, Science, 325, 5939 (2009) https://doi.org/10.1126/science.1172133

31. B. Walker, J.A. Meyers, Thresholds in ecological and social-ecological systems: A developing database, Ecology and Society, 25 (2004).

32. A. Guisan, N.E. Zimmermann, Predictive habitat distribution models in ecology, Ecological Modelling, 135 (2000) https://doi.org/10.1016/S0304-3800(00)00354-9

33. A. Dai, Increasing drought under global warming in observations and models, Nature Climate Change, 3 (2013) https://doi.org/10.1038/nclimate1633

34. R. A. W. Uk, Climate Models and Their Evaluation, Evaluation, 17 (2007) https://doi.org/10.1016/j.cub.2007.06.045

35. I.A. Rudskaya, D.G. Rodionov, Comprehensive evaluation of Russian regional innovation system performance using a two-stage econometric model, Espacios, 39, 4 (2018)

36. Y.N. Eldyshev, The law of global warming and its amazing consequences, Ecology and life, 6 (2009)

37. T. Widmann, M. Lenzen, Environmental and social footprints of international trade (2018) https://doi.org/10.1038/\%20s41561-018-0113-9

38. G. Myhre, K. Alterskjaer, Frequency of extreme precipitation increases extensively with event rareness under global warming, Scientific report, 18, 4 (2019) https://doi.org/10.1038/s41598-019-52277-4

39. A. Medvedkov, Adaptation to climate change: the global environmental and economic trend and its significance for Russia, Bulletin of the Moscow State Regional University, Natural Sciences, 3 (2018)

40. I. Makarov, Global climate change as a challenge to the global economy and the economy, HSE Journal of Economics, 4, 2 (2013)

41. L.V. Bondarenko, O.V. Maslova, A.V. Belkina, K.V. Sukhareva, Global climate changing and its after-effects, Bulletin of the Russian Economic University G.V. Plekhanova, 2, 98 (2018)

42. A. Sabunchi, Consequences of natural disasters in developing countries, Bulletin of RSMU, 11, 3 (2009)

43. K. Lesk, P. Rowhani, N. Ramankutty, The impact of extreme weather disasters on world crop production, Bulletin of RSMU, 18 (2015)

44. S. Hallegatte, Disasters' impacts on supply chains, Nature sustainability, 2 (2019) https://doi.org/10.1038/s41893-019-0380-5

45. F. Lamperti, V. Bosetti, Public costs of financial instability caused by climate (2018) https://doi.org/10.1038/s41558-\%20019-0607-5

46. Y. Stetsunich, Y. Busheneva, A. Zaytsev A, Framing public financial policy, in Proceedings of SPBPU IDE-2019, October 18-19, 2019, Saint-Petersburg, Russia (2019) 